\title{
PRIMARY CARBIDE SOLUTION DURING THE MELTING OF SUPERALLOYS
}

\author{
F. Beneduce, ${ }^{*}$ A. Mitchell, S. L. Cockcroft, and A. J. Schmalz \\ Department of Metals and Materials Engineering \\ University of British Columbia \\ Vancouver, B.C., Canada, V6T 1 Z4 \\ * Instituto de Pesquisas Tecnologicas \\ Sao Paulo, Brasil
}

\begin{abstract}
$\underline{\text { Abstract }}$
The MC carbides which are precipitated during the freezing of most superalloys are very stable chemical compounds, as are the equivalent nitrides. The latter have been shown to persist through melting and casting processes when the nitrogen levels are above the nitride saturation solubility, but it is not clear whether or not the MC carbides can behave in the same way when exposed to liquids containing carbon at less than the carbide solubility limit. This study was directed towards defining this situation.

A series of alloys containing various MC carbides was studied in respect of the carbide solution reaction through a melting and casting sequence. The "original" $\mathrm{MC}$ carbides could be distinguished from the "new" carbides in the final casting by means of their size distribution and also their composition. We found that in all cases except one, the carbides in the final cast product were produced during the final solidification and were not relics of the initial carbide structure before melting. The exception was found in the case of $\mathrm{HfC}$, but could have been due to the presence of a carbo-nitride of $\mathrm{Hf}$, and not to the reactions of a pure carbide.

We conclude that a conventional melting and casting procedure, as practiced in the investment casting or ingot making processes will serve to remove all memory of the initial carbide distribution from the product. Rapid melting $\left(>10^{3}{ }^{\circ} \mathrm{C} / \mathrm{s}\right)$ with negligible superheat followed immediately by a rapid solidification process $\left(>10^{3} \mathrm{C} / \mathrm{s}\right)$ would be required to retain any original carbides. The problem of carbide retention is hence restricted to some RST and powder production processes.
\end{abstract}

\section{$\underline{\text { Introduction }}$}

The question of whether or not the superalloy MC carbides can be retained through a melting and casting process has not been studied previously although there is one literature report (1) which suggests that in the case of IN 100 this is a possibility. In addition, there exists anecdotal evidence in the casting industry that the master alloy carbide structure has an influence on that of the cast product, although the specific influence has not been precisely reported

The MC carbides which are formed in the liquid/solid region of a superalloy casting depend on the alloy composition. In most cases they are a mixed $\mathrm{Nb}, \mathrm{Ti}$ carbide in which the ratio of $\mathrm{Ti}$ to $\mathrm{Nb}$ depends on the alloy and ranges from approximately $1: 2$ in high $\mathrm{Nb}$ alloys such as $\mathrm{IN} 718$, to pure $\mathrm{Ti}$ in the $\mathrm{Nb}$-free alloys such as IN 100. In alloys which contain $\mathrm{Hf}$, we find carbides which are essentially of Hf only, and also in Ta-rich alloys it is possible to identify pure Ta carbides. Since the MC carbides and TiN are isomorphous, they readily form solid solutions between them and amongst themselves. The question of the extent to which the "carbides" are in fact carbides and not carbo-nitrides has been addressed elsewhere (2), but since in most MC-containing alloys the nitrogen content is much smaller than the carbon content and in addition is principally present as TiN, we will initially assume that the $\mathrm{MC}$ carbides may be treated as pure carbide compounds for the purposes of thermochemical calculations.

Using assumed values for the diffusion coefficients of the appropriate elements in the liquid alloy, it is shown in Appendix I that the anticipated dissolution time for typical carbide particle sizes is extremely short and that on thcorctical grounds we would not expect to see any carbide retention through an equilibrium melting process. However, since a practical system can possibly include substantial unsteady-state temperature fluctuations it is necessary to examine the problem from an experimental as well as a theoretical viewpoint.

\section{Fxperimental}

A series of alloys was chosen so as to exhibit the limiting range of $\mathrm{MC}$ carbides found in industrial superalloys. For convenience, one of these was an experimental composition, but the remaining three were common industrial alloys. The compositions of the alloys are given in Table $\mathrm{I}$, together with the composition of the principal MC carbide.

The alloys were solidified under vacuum in a directional solidification furnace which has been described elsewhere (3). The resulting cylindrical ingols $(2.5 \mathrm{~cm}$ Dia $\times 20 \mathrm{~cm}$ long) were trimmed to eliminate the ill-defined head structure and expose the coarse directional dendritic structure of the bulk ingot. The MC carbide size distribution and compositions were then characterised by a combination of quantitative metallography and SEM/WDS techniques. Typical DS structures were obtained with primary dendrite spacings of the order of $200 \mu \mathrm{m}$, as shown in Figure 1 for the sample of alloy MAR M247.

The alloy bars were then remelted by electron beam in the apparatus shown schematically in Figure 2. The experimental objectives were to capture the bars' melting surfaces by vacuum quenching; to collect the liquid drops from the melting surface by a rapid chilling technique; and to collect the molten liquid in an ingot pool, but with a much different local solidification time than that experienced in the original fabrication of the DS bars. 
Examination of these three materials would then provide a determination of the carbide path through the melting process.

Table I Chemical Compositions in Wt \% or ppm of the Nickel Base Superalloy Melting Stocks

\begin{tabular}{|c|c|c|c|c|}
\hline \multicolumn{5}{|c|}{ Alloy (\%) } \\
\hline & INI00 & IN100HF & MM247 & IN718 \\
\hline C & 0.168 & 0.180 & 0.152 & 0.060 \\
\hline $\mathrm{Cr}$ & 99 & 9,5 & 83 & 19.5 \\
\hline Co & 15.0 & 15.0 & 10.0 & $<0.100$ \\
\hline w & - & - & 9.90 & $<0.100$ \\
\hline Mo & 3.26 & 3.00 & 0.64 & 3.05 \\
\hline $\mathrm{Nb}$ & - & - & - & 5,00 \\
\hline $\mathrm{Ti}$ & 4.45 & - & 980 & 1.02 \\
\hline Al & 5.46 & 550 & 5.61 & 0.55 \\
\hline B & 0.015 & 0.015 & 0.015 & 0.004 \\
\hline $\mathrm{Zr}$ & 0.050 & 0.060 & 0.030 & $<0.001$ \\
\hline $\mathrm{Fe}$ & - & 0.50 max. & - & bal \\
\hline $\mathrm{Ni}$ & bal. & bal. & bal. & 52.8 \\
\hline V & 0.97 & 0.95 & - & $<0.100$ \\
\hline $\mathrm{Ta}$ & - & - & 3.14 & $<05$ \\
\hline $\mathrm{Hf}$ & - & 4.50 & 1.40 & - \\
\hline$O(p p m)$ & 5 & & 1 & 3 \\
\hline $\mathrm{N}(\mathrm{ppm})$ & 9 & - & 3 & 16 \\
\hline Carbide & TiC & $\mathrm{HfC}$ & $\mathrm{TaC}$ & $\mathrm{NbC}$ \\
\hline
\end{tabular}

Figure I Optical micrograph of columnar zone of DS MM247

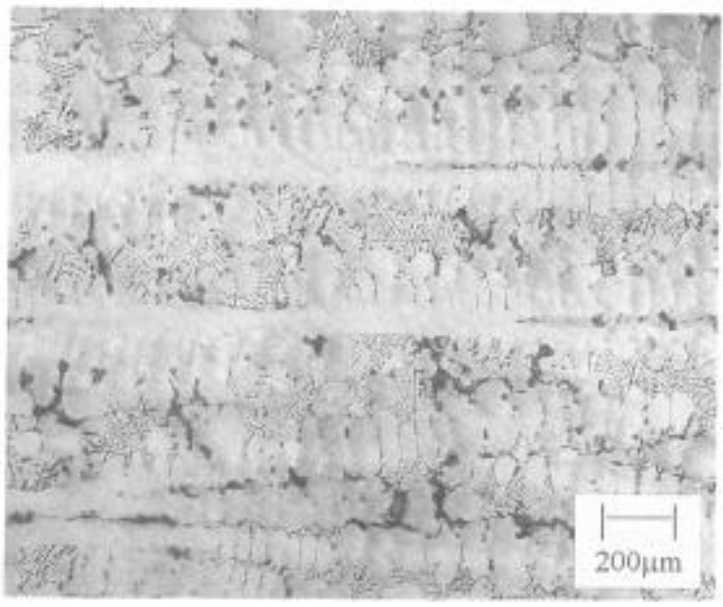

Figure 2: Schematic EB melting procedure of DS samples.

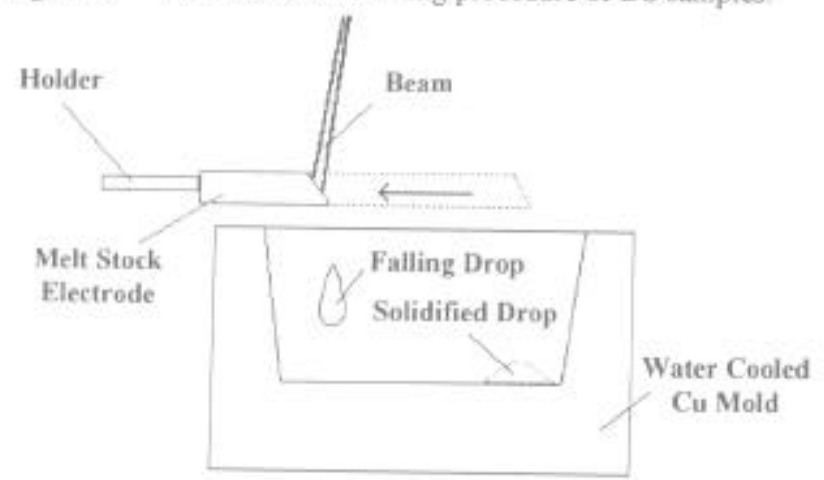

Figure 3a: Backscattered electron image in the columnar zone of DS MAR M247

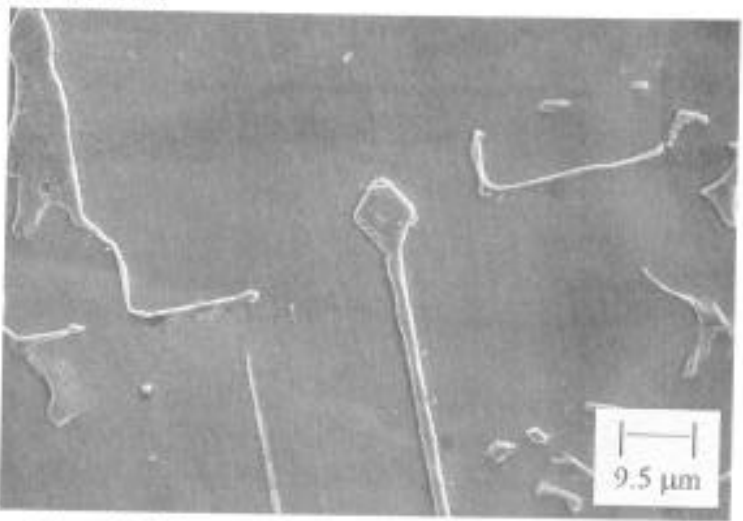

Figure 3b: Backscattered electron image in the columnar zone of EB MAR M247.

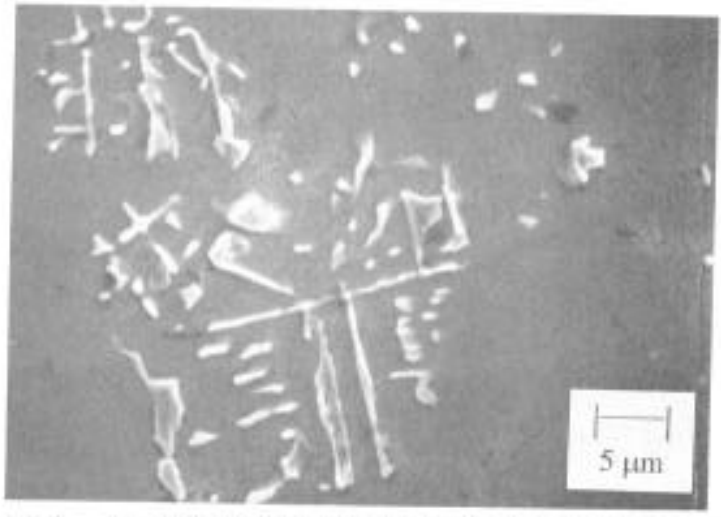

Figure 3c: Backscattered electron image in the columnar zone of DS IN718

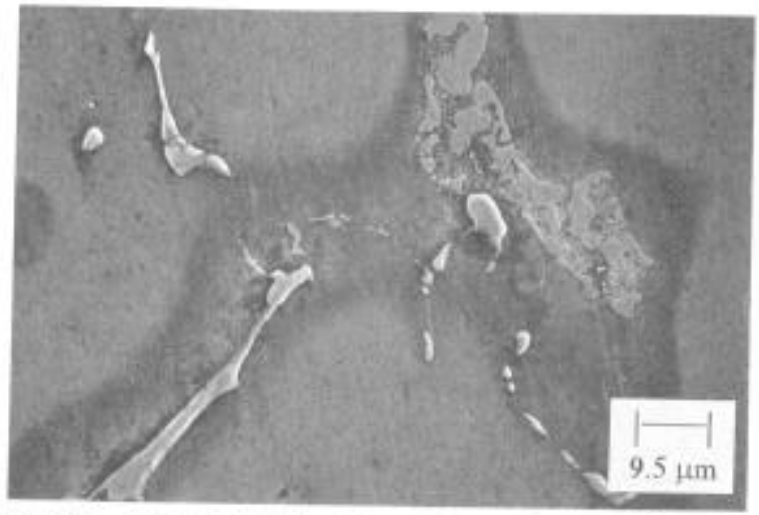

Figure 3d: Backscattered electron image in the chill region of an EB IN718 drop.

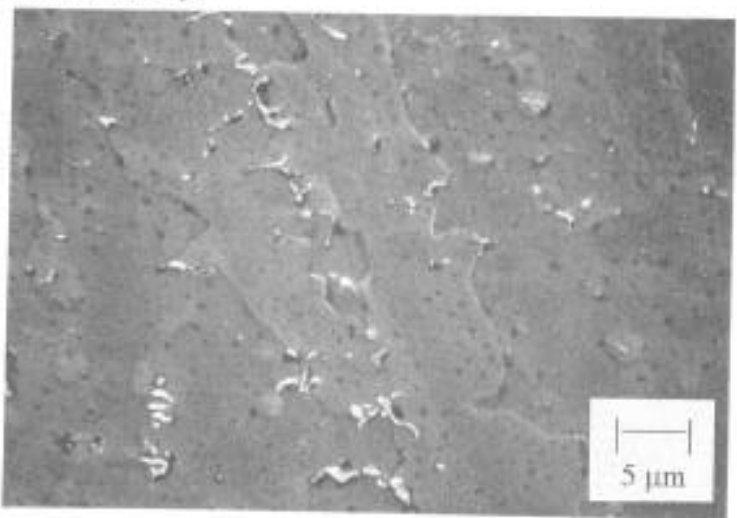


Figure 4: Backscattered electron image of a region near the chill plate in EB IN 100

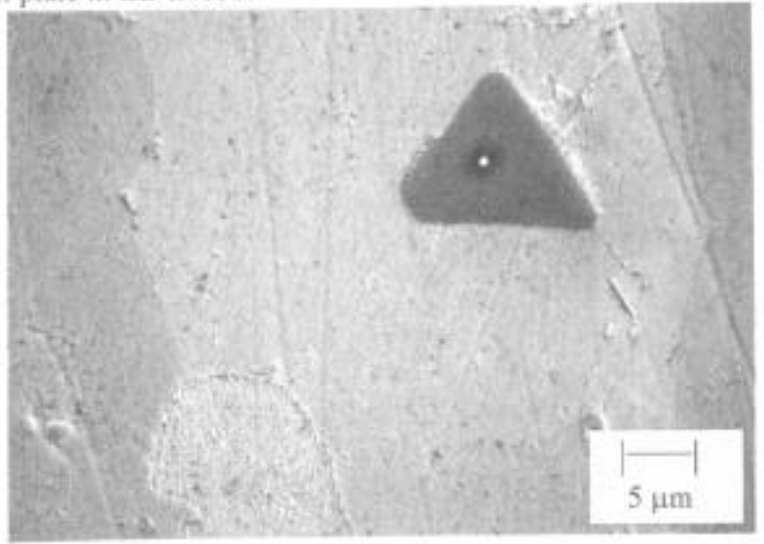

Figure 5a: Optical micrograph in the top region of the drop of EB IN100Hf.

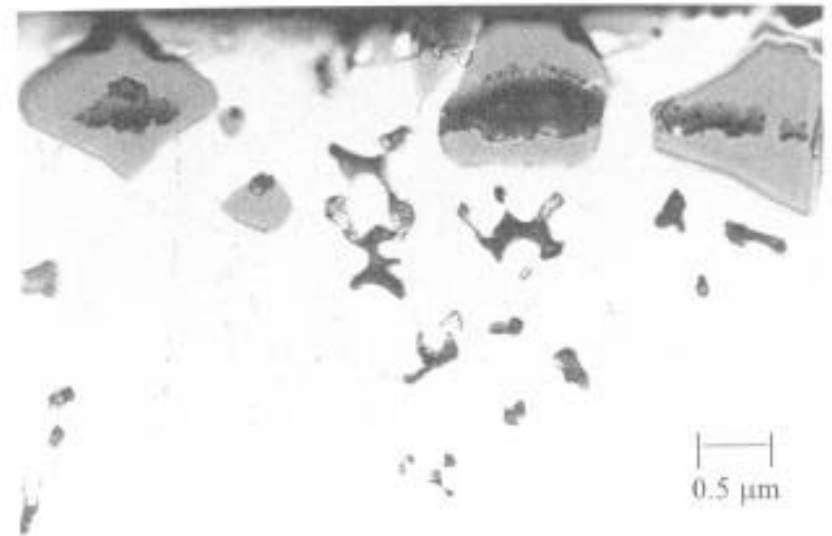

$\underline{\text { Results }}$

The results for the three commercial alloys are considered first. It was clear from an examination of the carbide size distributions that there was a great difference between the initial carbide size and that in the remelted material. Typical fields for two of the alloys are shown in Figure 3 Large carbide particles were specifically sought in all of the samples which had been EB processed, including in the search the free surface of the remelted samples, but none were found in alloys IN718, IN 100 or MAR M247.

Alloy IN 100 showed a clear retention of nitride particles, as shown in Figure 4.

The alloy $\mathrm{N} 100 \mathrm{Hf}$ showed large particles in and near the free surfaces of the remelted sample, as shown in Figures 5(a) and (b). which are in the same size range as those in the initial DS bar (Fig 5(c)). They are considerably larger than the primary dendrite arm spacing in the remelted samples and are clearly particles which have been retained through the melting process.

The carbide particles were analysed by EPMA in all cases. The results are summarised in Table II.

The analyses are complicated by the small size of the particles in the EB samples, and in some cases it was necessary to reduce the EPMA accelerating voltage to $10 \mathrm{kV}$ in order to minimise matrix interference. In the case of the alloy $\mathrm{IN} 100 \mathrm{Hf}$, the apparent nickel and cobalt content of the carbides is probably due to the matrix interference in the analysis, but the content of chromium and vanadium is thought to be valid.
Figure 5b: Optical micrograph in the region near the chill plate of EB IN100Hf.

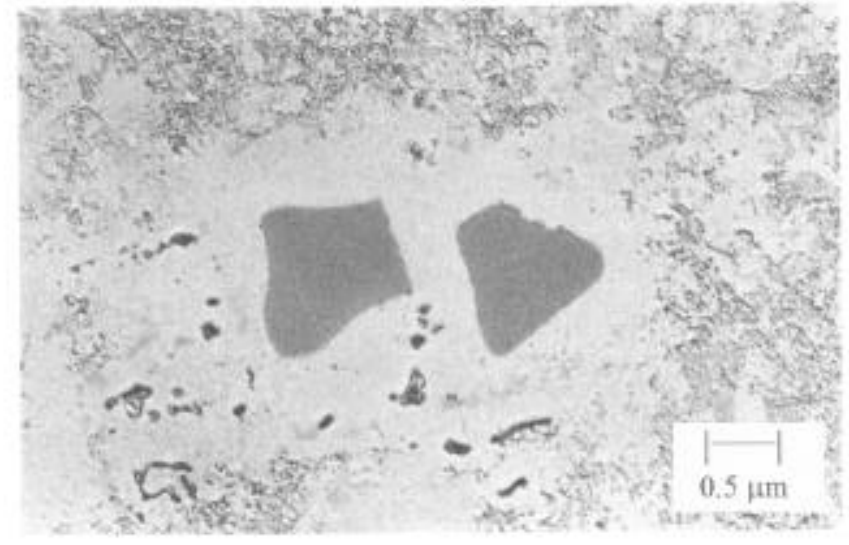

Figure $5 \mathrm{c}$ : Optical micrograph in the columnar region of DS IN10OHf

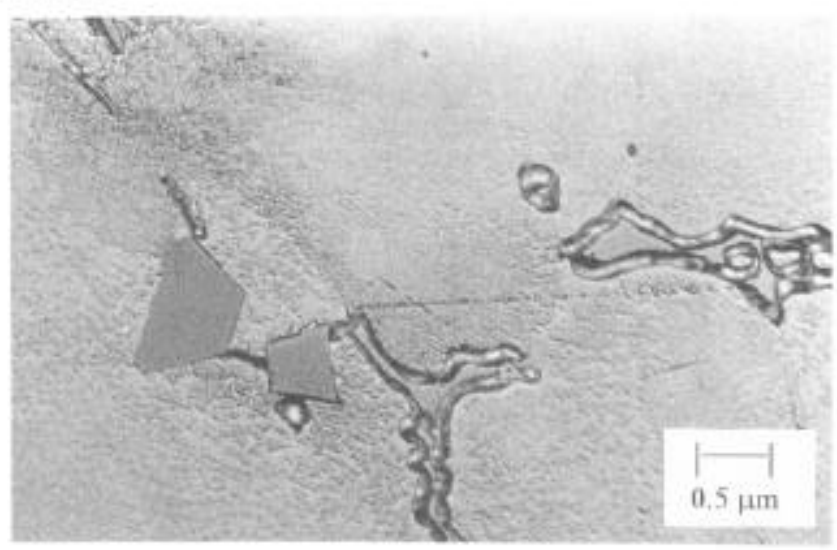

Table II Analyses of the Carbide Particles in Both DS and EB Structures

\begin{tabular}{|c|c|c|c|c|c|c|c|c|}
\hline & \multicolumn{8}{|c|}{ Alloy (\%) } \\
\hline & \multicolumn{2}{|c|}{ IN 100} & \multicolumn{2}{|c|}{ IN $100 \mathrm{HI}$} & \multicolumn{2}{|c|}{ MM 247} & \multicolumn{2}{|c|}{ IN 718} \\
\hline & DS & EB & DS & EB & DS & EB & DS & EB \\
\hline $\mathrm{Cr}$ & 2 & 16 & - & 3.39 & 4 & 8 & 18.2 & 20.7 \\
\hline Co & & & & 2.54 & & & & \\
\hline $\mathbf{W}$ & & & & & 14 & 14 & & \\
\hline Mo & 19 & 17 & & & 6 & 4 & 4.9 & 3.2 \\
\hline $\mathrm{Nb}$ & & & & & & & 10 & 3 \\
\hline $\mathrm{Ti}$ & 71 & 60 & & & 31 & 22 & 16 & 0,7 \\
\hline Al & & & & & & & 1 & 0.5 \\
\hline $\mathrm{Fe}$ & & & & & & & 15 & 19.1 \\
\hline $\mathrm{Ni}$ & & & 2.91 & 20.81 & & & 49.3 & 53 \\
\hline V & 4 & 5 & - & 1.06 & & & & \\
\hline $\mathrm{Si}$ & 4 & 2 & & & & & & \\
\hline $\mathbf{T a}$ & & & & & 39 & 39 & & \\
\hline Hf & & & 97.09 & 73.25 & 6 & 25 & & \\
\hline
\end{tabular}

\section{Discussion}

As emphasized in Appendix 1, the solution rate of the small carbide particles found in the initial DS samples should be high The melting period on the tip of the electron-beam melted sample 
was difficult to estimate but lies between 5 and 10 seconds, which is well above the millisecond period estimated in Appendix 1 for the liquidus temperature. Examination of the melting interface indicates no carbides of the original size (in alloys IN718, IN100 and MAR M247) in the region which was processed above the MC precipitation start temperature i.e. in the region where carbide solution should have taken place. In the case of $\mathrm{TiC}$, the carbide particles are less dense than the parent alloy and might have shown some flotation behaviour, but this was not observed in the vertically-grown DS samples. They are also not found to be present in any raft on the EB sample free surface. The remaining MC carbides in the alloys tested are all much more dense than the parent alloy.

The nitride behaviour is of some interest also. In the alloy IN718, the nitrogen content was sufficiently low $(15 \mathrm{ppm})$ that the nitride solution temperature was at the first eutectic melting point. It would be anticipated therefore, that nitride particles would not be seen in the structure, and also that the "carbide" particles would be carbides and not carbonitrides. No TiN particles were observed in any of the IN718 samples in other than the eutectic pools. In the alloy $\mathrm{IN100}$, however, the higher Ti content renders TiN much less soluble and as expected, TiN particles are observable in all samples. The EB processed alloy shows TiN particles in a size range which indicates that they passed directly through the process without melting, and also had a propensity to form a "raft" on the EB alloy's free surface. These massive particles are also seen to be an effective nucleant for the MC carbide (Figure 4) in spite of the rapid chill. TiN (density $5.22 \mathrm{Kg} / \mathrm{m}^{3}$ ) particles have been observed previously (4) to float in liquid IN100 which was not superheated to a temperature above their solution temperature in an alloy with approximately $10 \mathrm{ppm}$ nitrogen (the liquidus saturation solubility of TiN in $\mathrm{IN} 100$ is $4.5 \mathrm{ppm} \mathrm{N}$ ) and so their part in a raft formation in the EB button at low superheat is not unexpected.

As indicated above, the carbide behaviour in the three commercial alloys follows the expected solution process. The freezing process in the EB regime was sufficiently fast as to cause the composition of the carbide to deviate considerably from the equilibrium value. It can be seen from Table II that in all cases, the chromium content is considcrably clevated in the EB material from the DS value. This effect is probably due to the fast chill process which restricts the diffusional gradient required to supply the minor elements to the precipitating particle and instead substitutes the next most stable carbide former from the matrix, i.e. $\mathrm{Cr}$. The effect is less well-defined in the alloy IN100Hf because the high atomic weight of Hf restricts the accuracy of analysis, particularly in small particles, but is nonetheless visible in the results shown in Table II.

The apparent retention of carbide particles through the melting process in the case of alloy IN $100 \mathrm{Hf}$ is interesting. These particles are seen (Figure 5(a)) to collect at the upper free surface of the EB button, which must be due to either a particle-pushing mechanism in the fast-freezing regime of the $\mathrm{EB}$ procedure or alternatively to a surface tension effect which keeps the particles on the free surface once they have been exposed on the surface of the melting DS feed bar. It can not be due to any bouyancy force, since HfC has a density of $12.2 \mathrm{Kg} / \mathrm{m}^{3}$, well in excess of that of the parent alloy.

Examination of the freezing interface in the manufacture of the initial DS sample showed that the carbides are initially precipitated at a temperature $30^{\circ} \mathrm{C}$ below the equilibrium liquidus temperature and should, therefore dissolve during the EB melting/freezing sequence in a manner closely following that of the other alloys studied. They are, however, seen in optical section to have colour gradients internally which suggest that they are not in fact pure carbides, but some combination of $\mathrm{HfC}$ and HfN. The larger particles were examined by light-element WDS and found to have a small nitrogen content;

$\mathrm{C}(\mathrm{wt} \%) 6.5 \quad \mathrm{~N}(\mathrm{wt} \%) \quad 4.5$

leading to an average particle composition which is quite close to $\mathrm{Hf}(\mathrm{NC})$. The extreme thermochemical stability of HfN would presumably lead to a very small solubility of this compound in the alloy (following the precedent of TiN in the similar matrix), and the large atomic size of $\mathrm{Hf}$ possibly stabilises the solid solution between the carbide and the nitride to an even greater extent than is found for the equivalent system based on $\mathrm{Ti}$. The "MC" precipitates in the experimental alloy IN100Hf would therefore appear to be very stable carbonitrides and have solution characteristics which are quite different from the pure carbides. In order to test this hypothesis it would be necessary to re-make the IN100Hf alloy with an extremely-low nitrogen content (below $1 \mathrm{ppm}$ ) so as to precipitate the pure carbide. In all practical alloys based on $\mathrm{Hf}$ additions, however, it seems probable that the "MC" precipitates are in fact carbonitrides and that they will accordingly have a finite probability of being carried through a melting process.

\section{Implications for Melting Practice}

It appears from the above work that the commercial superalloys would not exhibit retention of pure $\mathrm{MC}$ carbides through the conventional melting and casting processes even if the melt has little superheat and the melting step is rapid. In high energy dripmelting processes such as welding, surfacing or rotating electrode powder processes where the melting/freezing cycle is completed in a millisecond time scale, there is a possibility of carbide carry-over which could be identified by means of the $\mathrm{Cr}$ content in the product carbide compositions. Care must be taken, however, in applying these conclusions to systems in which the nitrogen content is high enough that the structure contains primary carbonitrides as well as carbides. The solubility of the carbonitrides is evidently significantly smaller than that of the pure carbide (particularly so in the case of Hf-containing alloys) as is that of the pure nitride, TiN, and it is very possible that these compounds will be carried through the melting/casting process without solution. In that case, not only will the particle size distribution of the initial material be important in determining the properties of the final product, but the particles will also influence the product carbide distribution through their effect on carbide nucleation during freezing.

\section{Acknowledgments}

The authors are grateful for financial support of this work through the Instituto de Pesquisas and the Nickel Development Institute. They would also like to acknowledge the generous support of the Special Metals Corporation, the Cannon-Muskegon Corporation and the Pratt-Whitney Corporation in supplying materials and analytical assistance. 


\section{References}

1. R. Mchrabian et al., "Interdendritic Fluid Flow and Macrosegregation; Influence of Gravity," Met. Trans., 1, (1970), 1209-1220.

2. S. L. Cockcroft, A. Mitchell and A. J. Schmalz, "Primary Carbide and Nitride Precipitation in Superalloys Containing Niobium," J. High Temperature Materials and Processes, 15 (1), (1996), 245 - 255.

3. Y. Haruna, A. Mitchell and A. J. Schmalz, "Some Observations on the Recycling of Superalloys by the EBCHM Process," J. High Temperature Materials and Processes, 14 (3), (1995), 173 - 191.

4. Y. Haruna, (M.A.Sc. Thesis, University of British Columbia, 1994).

\section{Appendix 1}

\section{THE SOLUTION RATE OF NbC IN LIQUID ALLOY IN718}

The development of an equation describing the solution rate of a particle in a liquid is given by Geiger and Poirier (1A);

$$
t=2 \rho_{s} D_{p} / 3 \rho_{1} \lambda k_{m}\left(C_{0}-C \infty\right)
$$

where; $\mathrm{t}$ is the time for complete solution (seconds).

$D_{p}$ is the dianter of the particle (m).

$\mathrm{C}_{0}$ is the weight fraction of $\mathrm{Nb}$ at the particle surface.

$\mathrm{C}_{\infty}$ is the weight fraction of $\mathrm{Nb}$ in the liquid distant from the particle surface.

$\mathrm{k}_{\mathrm{m}}$ is the mass transfer coefficient for the process (assumed to be $0.02 \mathrm{~cm} / \mathrm{sec}$ ).

$\lambda$ is a particle shape factor (assumed to 1.5 ).

$\rho_{\mathrm{s}}$ and $\rho_{1}$ are particle and liquid densities respectively $\left(\mathrm{Kg} / \mathrm{m}^{3}\right)$.

Substituting values into this relationship appropriate for $\mathrm{NbC}$ in alloy IN7 78 at $1630 \mathrm{~K}$, for a particle of 10 microns dimension, the complete solution time is estimated to be $150 \mathrm{msec}$. Since the parameter values are very similar for the other carbides considered in this study, it is likely that their solution times will also be comparable. The samples remelted hy FB in the present study were estimated to have a residence time in the temperature zone above the $\mathrm{MC}$ precipitation temperature of approximately 2 seconds.

\section{References}

1A. G. H. Geiger and D. R. Poirier; Transport Phenomena in Metallurgy, (New York, NY: Addison-Wesley, 1973), 541. 